\title{
Features of municipal-level election campaigns in the capitals of the Tver, Belgorod and Kostroma regions
}

\author{
A. G. Arutynov ${ }^{1}$, N. N. Kozlova², V. S. Solnyshkov³
}

1Regional Development Council of the Russian Association of Political Science, 84 Vernadsky Ave., Moscow, 119454,
Russian Federation
2Tver State University, 33 Zhelyabova str., Tver, 170100, Russian Federation
3Youth Chamber at the Duma of the City of Kostroma, 1 Sovetskaya str., Kostroma, 156000, Russian Federation

DOI: $10.18255 / 2412-6519-2021-4-350-357$

Research Article

Full text in Russian

The article deals with the peculiarities of the course of election campaigns in the municipal representative bodies of the cities of Tver and Kostroma. The article is part of a larger study on the peculiarities of the course of election campaigns in the capitals or administrative centers of the subjects of the Russian Federation in the Central Federal District, which focuses on the problems of three subjects and compares the research material from these subjects with general district trends and features. Tver, Belgorod and Kostroma represent a wide geographical range and three peculiar examples of the course of election campaigns in large municipalities. The study revealed such common features as low turnout, rather weak competitiveness, the use of black PR and other shadow technologies, the traditional representation of lobbying structures in municipal parliaments, as well as the mobilization of "parliamentary opposition parties" and small parties at the last election campaigns in the elections of the type we study. The article acquires particular importance within the framework of the work of the State Duma of the Federal Assembly of the Russian Federation (and subsequent legislative instances) on Draft Law No. 1256381-7 «On general principles of the organization of public power in the subjects of the Russian Federation», where special attention is supposed to be attributed to the order of election and aspects of regulation of the work of municipal parliaments of the capitals of the subjects of the Russian Federation.

Keywords: elections, Russian Federation, regions, municipal parliaments, Tver, Kostroma, Belgorod

\section{INFORMATION ABOUT THE AUTHORS}

\begin{tabular}{l|l} 
Arutynov, Anton G. & $\begin{array}{l}\text { E-mail: anton.arutynov.98@mail.ru } \\
\text { Member of the Council for Regional Development of the Russian Political } \\
\text { Science Association }\end{array}$
\end{tabular}

\begin{tabular}{l|l} 
Kozlova, Natalia N. & $\begin{array}{l}\text { E-mail: tver-rapn@mail.ru } \\
\text { Doc. Sc. (Politics), Associate Professor, Head of the Political Science }\end{array}$ \\
Departme
\end{tabular}

Department

\begin{tabular}{l|l} 
Solnyshkov, Vkadislav S. & $\begin{array}{l}\text { E-mail: solnyshkov.vlad@mail.ru } \\
\text { Chairman of the Youth Chamber at the Kostroma Duma }\end{array}$
\end{tabular}

For citation: Arutynov A. G., Kozlova N. N., Solnyshkov V. S. Features of municipal-level election campaigns in the capitals of the Tver, Belgorod and Kostroma regions // Social'nye i gumanitarnye znanija. 2021. Vol. 7, No 4. P. 350-357. (in Russ.)

(C) Arutynov A. G., Kozlova N. N., Solnyshkov V. S., 2021

This is an open access article under the CC BY license (https://creativecommons.org/licenses/by/4.0/) 


\title{
Особенности избирательных кампаний муниципального уровня в столицах Тверской, Белгородской и Костромской областей
}

\author{
А. Г. Арутюнов ${ }^{1}$, Н. Н. Козлова ${ }^{2}$, В. С. Солнышков ${ }^{3}$ \\ ${ }^{1}$ Совет по региональному развитию Российской ассоциации политической науки, пр. Вернадского, 84, \\ Москва, 119454, Российская Федерация \\ 2Тверской государственный университет, ул. Желябова, 33, Тверь, 170100, Российская Федерация \\ ${ }^{3}$ Молодёжная палата при Думе города Костромы, ул. Советская, 1, Кострома, 156000, Российская Федерация
}

DOI: $10.18255 / 2412-6519-2021-4-350-357$

Научная статья

УДК 342.849 .2

Полный текст на русском языке

В статье рассматриваются особенности избирательных кампаний в муниципальные представительные органы городов Твери, Белгорода и Костромы. Представленные в статье данные отражают результаты части масштабного проекта, направленного на выявление специфики избирательных кампаний в столицах/административных центрах субъектов Российской Федерации в Центральном Федеральном округе (далее - ЦФО). На примере трёх субъектов РФ ЦФО авторы анализируют региональные и общеокружные тенденции проведения избирательных кампаний. В ходе исследования были выявлены такие общие черты избирательных кампаний, как низкая явка избирателей, слабая конкурентность партий, использование технологий чёрного пиара и других теневых технологий, традиционная представленность лоббирующих структур в представительных органах местного самоуправления, а также мобилизация «партий парламентской оппозиции» и малых партий на последних избирательных кампаниях в муниципалитеты столиц субъектов Федерации. Статья приобретает особую актуальность в рамках работы Государственной Думы Федерального Собрания Российской Федерации (и последующих законодательных инстанций) над Законопроектом № 1256381-7 «0б общих принципах организации публичной власти в субъектах Российской Федерации», где отдельное внимание предполагается уделить порядку избрания и аспектам регуляции работы муниципальных парламентов столиц субъектов Российской Федерации.

Ключевые слова: выборы, Российская Федерация, регионы, муниципальные парламенты, Тверь, Кострома, Белгород

ИНФОРМАЦИЯ ОБ АВТОРАХ

\begin{tabular}{r|l} 
Арутюнов, Антон & $\begin{array}{l}\text { E-mail: anton.arutynov.98@mail.ru } \\
\text { Георгиевич }\end{array}$ \\
$\begin{array}{l}\text { Член Совета по региональному развитию Российской ассоциации } \\
\text { политической науки }\end{array}$
\end{tabular}

Козлова, Наталия | E-mail: tver-rapn@mail.ru

Николаевна Доктор политических наук, доцент, заведующая кафедрой политологии

Солнышков, Владислав $\quad$ E-mail: solnyshkov.vlad@mail.ru

Сергеевич $\quad$ Председатель Молодёжной палаты при Думе города Костромы

Для цитирования: Арутюнов А. Г., Козлова Н. Н., Солнышков В. С. Особенности избирательных кампаний муниципального уровня в столицах Тверской, Белгородской и Костромской областей // Социальные и гуманитарные знания. 2021. Том 7, № 4. С. 350-357.

(C) Арутюнов А. Г., Козлова Н. Н., Солнышков В. С., 2021

Статья открытого доступа под лицензией СС BY (https://creativecommons.org/licenses/by/4.0/) 


\section{Введение}

Муниципальные выборы в современной России представляют особый интерес ввиду большого многообразия форм их проведения [1, с. 243-250], влияния данного уровня выборов не только на городскую, но и на региональную политическую повестку, а также на организацию самих муниципалитетов. Кроме того, выборы муниципального образования столицы субъекта РФ становятся знаковым политическим событием как минимум в регионе их проведения [2, с. 108-112]. Сразу отметим, что большое количество экспертов и специалистов обращаются к данной проблематике в контексте решения общетеоретических вопросов, связанных с природой демократии, местного самоуправления и пр. [3, с. 307-311]. Эти исследования посвящены нормативно-правовым аспектам проведения муниципальных выборов, изучению отдельных кейсов и анализу муниципального типа кампаний как специфического электорального института [4; 5]. Наиболее актуальными для нашего исследования являются статья Н. С. Сахно, посвященная муниципальным выборам на материалах г. Геленжик, исследование А. Е. Любарева, в центре внимания которого выборы представительных органов местного самоуправления г. Новосибирска, г. Сыктывкара и г. Воркуты Республики Коми, г. Калуги Калужской области [6], а также исследование И. С. Амиантовой, анализирующей факторы успеха партии «Новые люди» на различного уровня выборах, в том числе в Костромскую городскую Думу [7], научную публикацию Т. И. Нигметзянова, рассматривающего муниципальные выборы в Костроме в единый день голосования 13 сентября 2015 года [8] и др. В качестве общего тренда муниципальных выборов исследователи называют низкую явку избирателей на муниципальных выборах, связывая ее с кризисом легитимности власти на местах и ростом абсентеизма граждан $[9 ; 10]$.

Для определения объекта исследования мы определили круг кейсов, к которым гипотетически отнесли выборы в столицах/административных центрах 18 субъектов Федерации ЦФО. Однако под параметры исследования не подошли два субъекта РФ ЦФО - город федерального значения Москва и Московская область, которые не имеют своих столиц или административных центров как фактических территорий. Административный центр Московской области в Красногорске или Москве нельзя считать столицей, так как его нормативный статус не схож со столицами/административными центрами других областей ЦФО. Таким образом, авторы данной статьи сконцентрировали внимание на выборах в муниципальные представительные органы 16 городов ЦФО, находящихся на территории столицы/административного центра субъекта Российской Федерации, не анализируя выборы в представительные органы городских районов, иных поселений, включённых в состав муниципалитета (деревни, посёлки или иный формы муниципальных объединений).

В качестве первых промежуточных итогов нашего исследования мы предлагаем выявленные в ходе анализа особенности избирательных кампаний в Твери, Костроме и Белгороде, характерные исключительно для данных регионов, а также общие тенденции для трёх региональных столиц.

За деятельную помощь в проведении исследования мы хотим выразить благодарность Сковикову Алексею Константиновичу (г. Москва), Степанову Алексею Николаевичу (г. Липецк), Гуковой Ирине Николаевне (г. Белгород), Сизову Владиславу Олеговичу (г. Ульяновск), Звягиной Наталье Алексеевне (г. Воронеж), Сельцеру Дмитрию Григорьевичу (г. Тамбов), Евстифееву Роману Владимировичу (г. Владимир), Васильеву Андрею Михайловичу (г. Александров), Деркачу Максиму Андреевичу (г. Вышний Волочёк) и всему коллективу коллег-политологов ЕГУ им. И. А. Бунина (г. Елец).

\section{Методы}

В качестве основного инструмента исследования был выбран метод фокус-групп. В течение марта-мая 2021 года фокус-группы были проведены в Твери, Белгороде и Костроме. Кроме того, состоялись дополнительные фокус-группы в Москве и экспертное 
интервьюирование в Вышнем Волочке. Данные качественные исследования позволили привлечь большое количество экспертов политологов, политических практиков, специализирующихся в области избирательных процессов и обеспечить относительно широкий (с учетом размера ЦФО) географический разброс исследования.

Выбор фокус-групп как главного метода исследования был детерминирован тем, что данный метод способен отразить реальную картину протекания политических и электоральных процессов, поскольку представляет фокусированное мнение и позиции экспертов, способен эксплицировать объективные факты общественной жизни региона, связанные с избирательным процессом, даёт возможность сопоставить выводы экспертов одного региона с выводами экспертов в целом по ЦФО. Эффективность применения метода фокус-групп в нашем исследовании усиливалась, во-первых, за счёт высокой компетентности экспертов; во-вторых, за счёт постановки списка вопросов со стороны модераторов фокус-группы (часть вопросов носила межрегиональный характер). Фокусгруппы проводились очно с соблюдением всех противокоронавирусных мер.

Первая фокус-группа в Твери была проведена в марте 2021 года на базе Тверского государственного университета как нейтральной, с политической точки зрения, площадке. На фокус-группе присутствовали депутаты Тверской городской Думы, представители органов государственной власти Тверской области, политологи Твери, члены политических партий, имеющих представительство в Твери и Тверской области. Поэтому можно говорить о достаточной репрезентативности привлеченного к исследованию экспертного сообщества. В апреле 2021 года были проведены аналогичные фокус-группы в Белгороде, а также в городе Москве. Последняя фокус-группа была проведена дополнительно для сопоставления результатов исследования в других региональных группах и подтверждения позициями не привязанных географически экспертов-«москвичей». В мае 2021 года в Костроме была проведена фокус-группа, в рамках которой с действующими депутатами обсуждалась актуальная проблематика костромских муниципальных выборов.

\section{Результаты}

В ходе обсуждения в Твери был выявлен ряд важнейших особенностей муниципальных выборов. В частности, участниками фокус-группы был назван такой тренд, как низкая явка избирателей и соответственно, низкий уровень мобилизации. Так, было отмечено, что низкая явка на муниципальных выборах Твери наблюдается на протяжении всех электоральных циклов выборов в городскую Думу и Главы города (в последнем случае - до отмены прямых выборов Главы города Твери). Участники фокус-группы отмечали, что явка возрастает при совпадении муниципальных выборов с другими избирательными кампаниями, к примеру, выборами в Государственную Думу ФС РФ или региональные органы государственной власти. Причины низкой явки избирателей были названы экспертами весьма разнообразные: непонимание электоратом функций представительного органа местного самоуправления и, следовательно, недооценка значимости самой кампании со стороны представителей электората, падение значимости политического веса Тверской городской Думы, когда большая часть городских функций была передана на региональный уровень. Ряд экспертов выдвигал версии об искусственном происхождении низкой явки, поскольку излишняя политизация могла бы привести к трудно предсказуемым результатам голосования, неудовлетворительным для большинства политических акторов региона. Отметим, что эксперты отвергали использование такой избирательной технологии, как джерримендеринг на рассматриваемом нами уровне (если речь идёт сугубо о муниципальных выборах без совпадения по времени с параллельными кампаниями). Участвующие в фокус-группе представители «Единой России» и оппозиционных партий не сошлись во мнении относительно характера протекания избирательной кампании: если первые утверждали, что выборы были «очень тихие, не было ни вбросов, никаких скандалов, не 
было того, что бы могли снять папарацци», то члены партии «Родина», отмечая, что «чувствовалось влияние административного ресурса», напомнили, что в рамках избирательной кампании КПРФ подал иск в суд на их партию.

Особое внимание участники фокус-группы уделили вопросам предвыборной агитации. Эксперты называли характерные ошибки во время ведения избирательной кампании, касающиеся вопросов тиражирования и распространения материалов: распространение агитационных материалов вне округов проведения избирательной капании, неправильная маркировка источника финансирования на агитационных мероприятиях, проблемы с доступом к агитационным площадям, например, билбордам, реже к эфирному времени. Данные трудности отмечали представители партий «парламентской оппозиции» и малых партий, получившие места в муниципальных представительных органах рассматриваемых нами субъектов. На наш взгляд, указанные отличия кампании можно объяснить тем, что представители партий «парламентской оппозиции» и малых партий избираются не крепкими командами, переходящими из созыва в созыв, а имеют, скорее, ситуативный характер. Поэтому многие представители данных партий испытывают трудности ввиду отсутствия у них необходимых политологических и правовых знаний. Принимающий участие в фокус-группе сотрудник избирательной кампании отметила относительно представителей малых и позиционных партий, что «матчасть они, к сожалению, не читают, а чтобы включаться в процесс и контролировать его, необходимо понимание своих прав и избирательных процедур».

Участники фокус-группы отмечали недостаточно высокий технологический уровень избирательной кампании в Твери по сравнению с аналогичными процессами в Тамбовской и Новосибирской областях, в результате которых оппозиционные партии получили депутатские места. Представители оппозиционных и малых партий также указывали на применение технологий чёрного пиара и публикацию компромата. В качестве важной предвыборной стратегии они называли праймериз, которая позволяла начитать агитационную кампанию раньше, чем регламентировал законодатель. Эксперты также отмечали проблемы с финансированием избирательных кампаний, а именно неправильные способы сбора денежных средств для проведения предвыборной агитации, что, как указывают исследователи, является типичной ошибкой на муниципальных уровнях многих регионов РФ.

Спецификой кампании в Тверскую Городскую Думу 2017 года явился также тот факт, что последний раз в Тверской области использовалась строка «против всех». Исключительной характеристикой выборов в Твери является нормативная возможность голосования иностранных граждан некоторых государств, постоянно проживающих в городе Твери. В других субъектах эксперты не рассматривали данную практику даже как гипотетически применимую.

В Белгороде эксперты фокус-группы отмечали крайнюю замкнутость муниципальной политической системы, в том числе и на уровне Белгородского городского совета, незначительное количество политических сил, которые претендовали на вхождение в городской совет. В первую очередь это «представители партии власти» и представители «партий парламентской оппозиции», из которых наибольшей устойчивостью обладает КПРФ. Среди особенностей собственно избирательных кампаний эксперты называли типичную практически для всех регионов исследования ошибку в области агитации, в частности, агитация кандидата одного округа может распространяться в другом округе, порой географически весьма удалённом от округа избрания. Участники фокус-группы отмечали, что избиратели традиционно проявляют мало интереса к программным документам кампаний кандидатов, а кандидаты глубинно не работают над своей программой. Активные большие и яркие агитационные мероприятия являются скорее редкостью, чем правилом. 
Участвующие в фокус-группе кандидаты от партий парламентской оппозиции заявляли о трудностях при регистрации кандидатов или ведении кампании, несмотря на то, что они смогли преодолеть преграды и избираться в городской совет. По мнению экспертов, кампания в целом проходила без серьёзных скандалов, в медийном поле она освещалась слабо. Эксперты также называли такую особенность выборов в Белгородскую городскую Думу, как стремление региональных элитных групп лоббировать свои интересы в городском парламенте. В частности, были зарегистрированы кандидаты, аффилированные с группами бизнесменов или кампаний, специализирующихся на строительстве, прокладке и содержании дорог и так далее.

Специфика костромского материала обусловлена прежде всего тем, что в 2020 году в Костромской области совпали сразу три избирательных кампании: выборы губернатора Костромской области, выборы в городскую и областную Думы. Ранее проводимые исследования выборов в Костромской области фиксировали ряд отличий кампании в Костромскую городскую Думу, которые при проведении фокус-группы были также отмечены, а значит, они носят характер устойчивого тренда [8, с. 236-239].

Самая яркая тенденция - это неформальное, но устойчивое объединение городских кандидатов в депутаты Думы города Костромы со своими областными коллегами. Работа в такой связке позволила сэкономить на агитаторах и агитационном материале. Причем такие группы были свойственны не только «партии власти», но и беспартийным кандидатам. Важно также заметить, что перед выборами в Костромскую городскую Думу было принято решение перейти полностью на мажоритарную избирательную систему. Эксперты отмечали применение на костромских выборах такой важной избирательной технологии, как составление базы своих сторонников и постоянная работа с ними. К примеру, «Единая Россия» в мае 2020 г. проводила процедуру предварительного голосования, впервые используя возможность голосования дистанционно. Эксперты указывали, что, несмотря на то, что площадка праймериз была создана для предоставления возможности баллотироваться каждому гражданину и выявления сильных кандидатов, по факту все кандидаты были разделены «партией власти» на реальных и технических. В частности, на создание предвыборных роликов разным кандидатам был выделен разный объем денежных средств и предоставлены разные технические возможности: одних депутатов снимали на фоне белой стены, других - в профессиональной студии и т.д. В итоге технология праймериз позволила «Единой России» не только раньше других партий вступить в политическую борьбу, но и сформировать базу сторонников.

Эксперты отметили важную роль партии «Новые люди» в избирательной кампании в Костромскую городскую Думу. Основным направлением работы данная молодая партия выбрала молодежную политику, проводя молодёжные форумы, игры и т. д., что характерно и для федеральной политики данной партии в целом [7, с. 3129-3139]. Участники фокус-группы отмечали феномен сплочения вокруг «Новых людей» значительной группы политически активной молодежи. Эксперты высказывали точку зрения, что до появления партии «Новые люди» молодёжная политика в Костроме в основном была представлена «Молодой Гвардией» (далее - МГЕР), которая не пользовалась популярностью у оппозиционно настроенной части молодежи. Эксперты отмечали, что значительный объем финансирования деятельности «Новых людей» в рамках выборов в Костромскую городскую Думу, позволивший партии сделать современный ремонт в офисе, приобрести новую технику, разработать качественный мерч и логотип, создавали привлекательную атмосферу для молодежи.

Участники фокус-группы выявили и другие эффективные стратегии «Новых людей», применяемые на выборах в Костромскую городскую Думу. Вступить в избирательную гонку до официального начала выборов «Новым людям» удалось благодаря широкомасштабным акциям по раздаче санитайзеров: любой желающий мог оставить заявку 
на сайте партии или в социальных сетях. Создав за 4 месяца значительный штаб волонтеров для доставки санитайзеров нуждающимся гражданам, партия мобилизовала молодежный электорат, существенно повысила узнаваемость партии у населения, сформировала положительное отношение костромичей к новой партии. Остальные политические партии провели весну и начало лета пассивно, изредка устраивая пикеты и распространяя газеты.

Эксперты фокус-группы из Костромы отметили еще один сюжет, отличающий специфику выборов в Костромскую городскую Думу в 2020 году. В середине лета в медийном пространстве региона стал популяризироваться проект «Народный бюджет», суть которого сводилась в выделении федеральным центром субсидии на благоустройство города Костромы и области, а распределение данных средств по конкретным объектам предлагалась сделать жителям на избирательных участках с отдельными урнами для голосования по проекту «Народный бюджет». С точки зрения экспертов фокус-группы, несмотря на позиционирование данной программы как региональной, по факту ее можно было считать планом действий партии «Единая Россия». Работа по проекту была распределена на три этапа. Первый шаг в реализации проекта «Народный бюджет» - «хождение агитаторов в народ» (по квартирам жильцов), ознакомление жителей с деталями проекта, сбор данных об актуальных проблемах благоустройства территорий и т. д. На втором этапе агитаторы интенсифицировали контакты с людьми, которые положительно реагировали на их первое посещение. Агитаторы сообщали, что «Народный бюджет» курирует действующий депутат «Единой России», которому необходима поддержка на предстоящих выборах, а также распространяли агитматериалы за депутатов-кандидатов в Думу города Костромы и Костромскую областную Думу. На третьем этапе агитаторы раздавали пригласительные билеты и карточки предварительной регистрации по проекту «Народный Бюджет», которые можно было заполнить заранее и в день голосования обменять их на бланк голосования по народному бюджету вне очереди. Таким образом, по мнению экспертов, «Единая Россия» аккумулировала базу своих сторонников, раздав приглашения на выборы только тем, кто поддерживает партийных кандидатов от данной партии. Участники фокус-группы со стороны оппозиционных партий отмечали, что в данных обстоятельствах бороться за депутатские места в Костромскую городскую Думу было особенно тяжело, а потому в рамках их избирательных стратегий использовались традиционные технологии: встречи с жителями, работа через старших по дому, повсеместное распространение и расклейка агитационных материалов и т. д. Отметим, что эксперты из московской фокус-группы, анализирующие кампании в Твери, Белгороде, Костроме, также отметили тренды на низкую активность избирателей, наличие лобби региональных элитных групп во время избирательных кампаний, характерные ошибки в пиаре.

\section{Выводы}

Таким образом, все три региона имеют как общие, так отличительные черты при проведении избирательных кампаний в своих столицах/административных центрах. В качестве особенностей, которые характерны для города Твери, можно назвать в первую очередь специфику нормативно-правового поля - предоставление права избирать иностранным гражданам ряда стран, наличие в бюллетене строки «против всех». Во вторую очередь следует выделить особенности протекания кампании: низкий уровень политической мобилизации, типичные ошибки в рамках агитационных кампаний, недостаточно высокий технологический уровень избирательной кампании. В Белгороде специфика городских выборов определялась замкнутостью местной политической системы и наличием лоббирующих групп, стремящихся оказывать влияние на выборы в представительный орган местного самоуправления. В Костроме отличительными чертами городских выборов явились наличие устойчивого объединения городских кандидатов в депутаты 
Думы города Костромы со своими областными коллегами (в силу хронологического наложения областных и городских выборов), мажоритарный тип избирательной системы, применение стратегии праймериз «Единой Россией», позволяющей раньше остальных партий вступить в предвыборную гонку, разработка предвыборных программ на основе финансовых и административных ресурсов государства (проект «Народный бюджет»), а также активность новой политической силы - партии «Новые люди».

К общим чертам можно отнести наличие фактора низкой явки, недостаточную конкурентность на выборах, относительно тихий, спокойный характер протекания избирательных кампаний, распространенные ошибки в агитационных кампаниях отдельных партий и кандидатов, использование некоторых теневых технологий, малую ценность городских выборов в глазах избирателей, а также наличие лоббирующих групп, которые стремятся провести своих кандидатов в муниципальные думы. Соотнеся полученные данные с итогами фокус-группы в Москве, а также экспертными интервью в Вышнем Волочке и Владимире, мы можем предположить, что указанные черты городских выборов в Твери, Белгороде и Костроме с высокой долей вероятности могут быть экстраполированы на уровень всего ЦФО РФ.

\section{Ссылки / References}

1. Сахно Н. С. Особенности проведения муниципальных выборов // Эпомен. 2019. № 32. C. 243-250.

2. Семенова А. В., Ароян А. С. Избирательные системы на региональных и муниципальных выборах // Местное самоуправление в условиях глобальных вызовов современной России: сборник докладов «круглого стола» молодых ученых в рамках научно-практической конференции с международным участием. Ростов н/Д.: ЮРИУФ РАНХиГС, 2019. С. 108-112.

3. Фисенко Е. С. Муниципальные выборы как право граждан на осуществление местного самоуправления // Вопросы теории и практики избирательного законодательства, посвященные 25-летию избирательной системы Краснодарского края: Материалы межвузовской научно-практической конференции, Краснодар, 04 июня 2019 года / под общ. ред. А. Д. Черненко; отв. ред. Н. Ю. Турищева. Краснодар: Издательский Дом - Юг, 2019. С. 307-311.

4. Долгих Ф. И. Муниципальный фильтр на региональных выборах: проблемные точки и правовые параметры оптимизации // Избирательное законодательство и практика. 2019. № 2. C. 15-19.

5. Токарева П. В., Корсенюк А. И. Нормативно-правовое регулирование порядка финансирования муниципальных выборов и контроля за его осуществлением: современное состояние и проблемы // Общество. Наука. Инновации (НПК-2019): Сборник статей XIX Всероссийской научно-практической конференции: в 4-х томах. Т 4. Киров, 01-26 апреля 2019 года. Киров: Вятский государственный университет, 2019. С. 526-534.

6. Любарев А. Е. Исследование совмещенных выборов: региональные и муниципальные выборы 2020 г. // Вестник Пермского университета. Политология. 2021. Т. 15. № 2. С. 96-109.

7. Амиантова И. С. Факторы успеха партии «Новые люди» в ходе региональных выборов 2020 г. в России // Вопросы политологии. 2020. Т. 10. № 11 (3). С. 3129-3139.

8. Нигметзянов Т. И. Муниципальные выборы в Костроме в единый день голосования 13 сентября 2015 года: избирательная система и избирательный процесс // Вестник Костромского государственного университета. 2016. Т. 22. № 2. С. 236-239.

9. Туровский Р. Ф., Корнеева Е. М., Васеленко О. С. Электоральная активность на муниципальных выборах в посткоммунистических странах // Мировая экономика и международные отношения. 2020. Т. 64. № 10. С. 121-132.

10. Х Хубаева Д. Ф. Абсентеизм на муниципальных выборах в Российской Федерации // Юридический вестник Самарского университета. 2020. Т. 6. № 3. С. 133-138. 